$18-25$

\title{
Risk factors for cardiac complications after spine surgery
}

\author{
Authors Juan P Guyot ${ }^{1}$, Amy Cizik², Richard Bransford ${ }^{1}$, Carlo Bellabarba ${ }^{1}$, Michael J Lee ${ }^{2}$ \\ Institution ${ }^{1}$ Harborview Medical Center, Department of Orthopedics and Sports Medicine, Seattle, Washington, USA \\ ${ }^{2}$ University of Washington, Department of Orthopedics and Sports Medicine, Seattle, WA, USA
}

\begin{tabular}{|c|c|}
\hline \multicolumn{2}{|l|}{ Methodological principle: } \\
\hline \multicolumn{2}{|l|}{ Study design: } \\
\hline Prospective cohort & \\
\hline Retrospective cohort (registry) & $\bullet$ \\
\hline Case control & \\
\hline Case series & \\
\hline \multicolumn{2}{|l|}{ Methods } \\
\hline $\begin{array}{l}\text { Patients at similar point in course } \\
\text { of treatment }\end{array}$ & - \\
\hline Follow-up $\geq 85 \%$ & • \\
\hline $\begin{array}{l}\text { Similarity of treatment protocols } \\
\text { for patient groups }\end{array}$ & - \\
\hline $\begin{array}{l}\text { Patients followed for long enough for } \\
\text { outcomes to occur }\end{array}$ & - \\
\hline Control for extraneous risk factors & $\bullet$ \\
\hline Evidence class: & II \\
\hline
\end{tabular}

The definiton of the different classes of evidence is available on page 73 .

\section{ABSTRACT}

Study design: Registry study using prospectively collected data

objective: To determine risk factors for cardiac complications in spine surgery.

Methods: The Spine End Results Registry 2003-2004 is an exhaustive database of 1,592 patients who underwent spine surgery at the University of Washington Medical Center or Harborview Medical Center. Detailed information regarding patient demographic, medical comorbidity, surgical invasiveness and adverse outcomes were prospectively recorded. The primary outcome of measure was the occurrence of a cardiac complication in the perioperative period. Relative risk (RR) and 95\% confidence intervals were calculated for each of the categorical variables. Multiple log-binomial regression analysis was performed to investigate the independent factors associated with cardiac complication.

Results: The incidence of cardiac complication after spine surgery was $6.7 \%$. There were 136 cardiac complications in 107 patients after spine surgery. Age, diabetes, previous cardiac history, elevated adjusted Charlson comorbidity score, revision surgery, combined anterior-posterior approaches, and surgical invasiveness were statistically significant risk factors for cardiac complication after spine surgery.

Conclusions: The results of the present study suggest numerous statistically significant risk factors for cardiac complications after spine surgery. These results may aid the clinician with preoperative risk stratification and patient counseling.

UWMC IRB-approved

Supported by grants from the NIH/NIAMS 5K23AR48979 and 5P60-AR48093 and supported in part by the Spine End-Results Research Fund at the University of Washington Medical Center through an endowment from the HansJoerg Wyss Foundation. 


\section{STUDY RATIONALE}

Numerous studies have examined the morbidity and mortality of spine surgery [1-9], however, there is a paucity of literature examining the occurrence of cardiac complications after spine surgery. Cardiac complications are a leading cause of death after non-cardiac surgery [4, $5,10]$. Lee et al reported a $0.8 \%$ incidence of cardiac complications after lumbar fusion in retrospective review of 901 patients [11], but identification of statistically significant risk factors was limited by the study methodology.

\section{OBJECTIVE}

The objective of this study is to identify risk factors for cardiac complications after spine surgery.

\section{Figure 1 Patient selection and sampling}

\begin{tabular}{|c|c|c|c|c|}
\hline $\begin{array}{l}\text { Enrollment } \\
\text { Total patients who underwent } \\
\text { spinal surgery at University of } \\
\text { Washington Medical Center and } \\
\text { Harborview Medical Center in } \\
\text { Seattle WA from Jan 1, } 2003 \text { to } \\
\text { Dec } 31,2004 \\
(N=1,745)\end{array}$ & $\begin{array}{l}\text { Study population } \\
\begin{array}{l}\text { Excluded } \\
(n=138)\end{array} \\
\text { Reasons: } \\
\text { - Age }<18 \text { years }(n=38) \\
\text { - Surgical invasiveness } \\
\text { score of } 0(n=100)\end{array}$ & $\begin{array}{l}\text { Not available } \\
\text { for analysis } \\
(\mathrm{n}=15) \\
\text { Reason: } \\
\text { - Missing surgical } \\
\text { invasiveness score } \\
\text { data }(n=15)\end{array}$ & $\begin{array}{l}\text { Available for } \\
\text { analysis } \\
(n=1,592)\end{array}$ & $\begin{array}{l}\text { With cardiac } \\
\text { complication } \\
(n=107)\end{array}$ \\
\hline
\end{tabular}




\section{METHODS}

Study design: Registry study using prospectively collected data.

\section{Inclusion criteria:}

- All patients who underwent spinal surgery from January 1, 2003 to December 31, 2004 at Harborview Medical Center and the University of Washington Medical Center, Seattle, Washington.

\section{Exclusion criteria:}

- Patients younger than 18 years of age

- Patients with incompletely recorded surgical invasiveness scores were not available for analysis.

- Patients with surgical invasiveness scores of 0 , as these included patients who did not undergo spinal surgery (Risser casting or closed reduction under general anesthesia)

Patient population: The Spine End Results Registry at the University of Washington Medical Center is a prospectively recorded database of patients who underwent spinal surgery from January 1, 2003 to December 31, 2004 at Harborview Medical Center or the University of Washington Medical Center in Seattle WA. Detailed information regarding patient demographic, medical comorbidity, surgical invasiveness and adverse outcomes were prospectively recorded as described by Mirza et al [12, 13]. All patients were followed for at least 2 years prospectively for cardiac complications.

Outcome: The primary outcome measure was the occurrence of a cardiac complication in the 2-year follow-up period. A detailed list of all cardiac complications and operational definitions and thresholds we used are summarized in Table 3.

\section{Analysis:}

- Categorical data were presented as number of events and percentages.

- Continuous data were presented as mean \pm standard deviation.

- Univariate analysis evaluating the association between each categorical variable and a pulmonary complication was performed using Pearson's Chisquare test or Fisher's exact tests (where cell counts were low).

- Univariate analysis evaluating the association between each continuous variable and a pulmonary complication was performed using unpaired t-tests.
- Multivariate log-binomial regression was used to determine the association between each risk factor and a pulmonary complication, while controlling for other predictive factors.

- Risk factors were included in the multivariate logbinomial regression model if they were deemed of clinical importance by the study investigators or if their univariate association had a $P$-value <.10.

- We examined diabetes and prior cardiac history as individual risk factors and subsequently examined and adjusted Charlson comorbidity score minus these two components (Table 2) [15].

\section{Table 1 Cohort characteristics}

\begin{tabular}{ll}
\hline & $\mathbf{N}=\mathbf{1 , 5 9 2}$ \\
\hline Age, years (mean \pm SD) & $49.6 \pm 16.0$ \\
\hline Male, $\mathrm{n}(\%)$ & $914(57 \%)$ \\
\hline Currently smoke, $\mathrm{n}(\%)$ & $488(32 \%)$ \\
\hline Illicit drug use, $\mathrm{n}(\%)$ & $167(12 \%)$ \\
\hline Alcohol use, $\mathrm{n}(\%)$ & $668(46 \%)$ \\
\hline Diabetes, $\mathrm{n}(\%)$ & $179(11 \%)$ \\
\hline $\begin{array}{l}\text { Previous cardiac incident, } \mathrm{n}(\%), \\
\text { includes angina, myocardial infarction, cardiovascular } \\
\text { vascular disease, congestive heart failure }\end{array}$ & $200(13 \%)$ \\
\hline Degenerative, $\mathrm{n}(\%)$ & \\
\hline Trauma, $\mathrm{n}(\%)$ & $992(62 \%)$ \\
\hline Neoplasm, $\mathrm{n}(\%)$ & $372(23 \%)$ \\
\hline Other diagnosis, $\mathrm{n}(\%)$ & $117(7 \%)$ \\
\hline Revision surgery, $\mathrm{n}(\%)$ & $111(7 \%)$ \\
\hline Anterior surgical approach, $\mathrm{n}(\%)$ & $286(18 \%)$ \\
\hline Posterior surgical approach, $\mathrm{n}(\%)$ & $292(18 \%)$ \\
\hline Combined surgical approach, $\mathrm{n}(\%)$ & $934(59 \%)$ \\
\hline
\end{tabular}

Table 2 Summary of conditions and weights used to calculate Charlson comorbidity score*

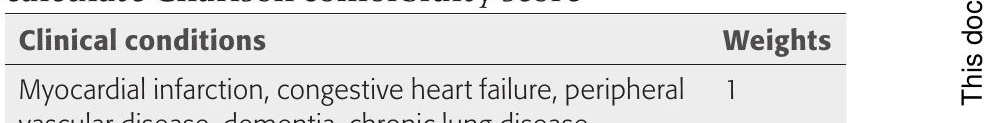
vascular disease, dementia, chronic lung disease, connective tissue disease, ulcer, chronic liver disease

Hemiplegia, moderate or severe renal disease, diabetes 2 with complication, tumor, leukemia, lymphoma

\begin{tabular}{ll}
\hline Moderate or severe liver disease & 3 \\
\hline Malignant tumor, metastasis, AIDS & 6 \\
* Weights are assigned to 19 predetermined clinical conditions with the \\
final score being the sum of the weights assigned to the conditions with \\
scores ranging from 0-37. One point for each additional decade of life \\
over 50-years-of-age can be added to initial score to create a single \\
index. The higher the weight total, the greater the likelihood of mortality.
\end{tabular}




\section{RESULTS}

- Of the 1,745 patients, 38 were not included because they were younger than 18 years of age and 100 were excluded for surgical invasiveness scores of 0 (Risser casting or closed reduction under general anesthesia). Fifteen had missing invasiveness scores, leaving 1592 patients for analyses (Figure 1).

- The mean age of the study population was 49.6 years. Thirty two percent smoked, $12 \%$ were illicit drug users and $11 \%$ had diabetes (Table 1).

- The incidence of cardiac adverse outcome after spine surgery was $6.7 \%$. There were 136 cardiac adverse outcomes in 107 patients after spine surgery (Table 3).

- In this patient population, there were 37 deaths within the 2-year period, of which 15 were cardiac related. The mortality rate from cardiac complications was 2.36 per 1000 persons per year.

- In the univariate analysis, age, diabetes, previous cardiac history, elevated adjusted Charlson comorbidity score [14], revision surgery, combined anterior-posterior approaches and surgical invasiveness were statistically significant risk factors for cardiac complication after spine surgery (Table 4).

- In the multivariate analysis, increasing age, elevated adjusted Charlson comorbidity score [14], and surgical invasiveness index were statistically significant risk factors for cardiac complication (Table 5).

\begin{tabular}{ll}
\hline Table $3 \quad$ Cardiac adverse occurrences & \\
\hline $\begin{array}{l}\text { Cardiac complications } \\
\text { Air embolism } \\
\text { Entrainment of air into the venous circulation and heart } \\
\text { detected by any monitoring device including Doppler, TEE, or } \\
\text { sudden decrease in end tidal CO2, SpO2, or blood pressure } \\
\text { or air in coronary vessels on post-mortem exam }\end{array}$ & $3(0.19 \%)$ \\
\hline $\begin{array}{l}\text { Arrest } \\
\text { Cardiac output insufficient to maintain a palpable central }\end{array}$ & $7(0.44 \%)$ \\
pulse, and requiring CPR, electroshock therapy and/or \\
vasoactive drugs to maintain an adequate perfusion \\
pressure.
\end{tabular}

\section{Arrhythmial}

Any cardiac rhythm which varies from baseline and requires

either extra monitoring, drugs, consultations, or electroshock therapy, or results in hypotension or death.

\section{CHF(new S3/JVD+rales/CXR+Tx)

An abnormality of cardiac function is responsible for the

failure of the heart to pump blood at a rate commensurate with the requirements of the metabolizing tissues, manifested by pulmonary edema, a new S3 gallop, jugular venous distension, rales, pleural edema or effusion, and requiring treatment.

\begin{tabular}{l} 
Hypertension \\
Sbp $>180$ or $\mathrm{Dbp}>100$ for $>5$ minutes \\
\hline $\begin{array}{l}\text { Hypotension(sBP/MAP }<50 \% \text { base, }>5 \mathrm{~min} \text { ) } \\
\text { Mean arterial pressure }<50 \% \text { of baseline for }>5 \text { minutes. }\end{array}$
\end{tabular}

Infarction(mc09+enzymes/new Qs) $48(3 \%)$

Necrosis of heart tissue as evidenced by elevated ST segments or new $\mathrm{Q}$ waves or new wall motion abnormality associated with elevated cardiac enzymes (troponin, CK-MB) Inappropriate or inadequate fluid therapy
Insufficient replacement of volume with blood products,
crystalloid or other colloid to maintain adequate perfusion
and oxygenation of all tissues, as evidenced by inadequate
urine output, low central filling pressures, elevated lactate,
metabolic acidosis with pH $<7.35$, and/or hypotension
responsive to fluids. Criteria: (1) inadequate urine output
$(<0.5 \mathrm{ml} / \mathrm{kg} / \mathrm{hr}) ;(2)$ hypotension responsive to fluid
challenge; (3) elevated lactate level; (4) metabolic acidosis
$(\mathrm{pH}<7.35) ;$ and/or (5) low central filling pressures.

\section{Ischemia(sx/1mmST 2 leads, ROMI/Tx)}

Myocardial ischemia is a deficiency of the blood supply to the

heart muscle, leading to symptoms, flat depression of the ST segment of more than $0.1 \mathrm{mV}$ below the baseline (ie, the PR segment) and lasting longer than $0.08 \mathrm{~s}$, treatment, or rule-out MI monitoring.

\begin{tabular}{ll}
\hline $\begin{array}{l}\text { Thermoregulation } \\
\text { Temperature }<35^{\circ} \mathrm{C} \text { for }>30 \text { minutes }\end{array}$ & 0 \\
\hline $\begin{array}{l}\text { Other cardiac occurrence } \\
\text { Other ciculation or cardiac-related occurrence }\end{array}$ & $11(0.7 \%)$ \\
\hline Total cardiac adverse occurences & 136 \\
\hline
\end{tabular}




\begin{tabular}{|c|c|c|c|c|c|}
\hline Risk factors & $\begin{array}{l}\text { Cardiac AO } \\
107\end{array}$ & $\begin{array}{l}\text { No cardiac AO } \\
1,485\end{array}$ & $\mathbf{R} \mathbf{R}$ & $95 \% \mathrm{Cl}$ & $P$-value \\
\hline Age (years ), mean (sd) & $64.4(14.2)$ & $48.5(15.5)$ & & & $<0.001$ \\
\hline $18-39$ & $7(2 \%)$ & $424(98 \%)$ & 1.00 & - & \\
\hline $40-64$ & $41(5 \%)$ & $818(95 \%)$ & 2.94 & $1.33-6.50$ & $<.001$ \\
\hline$\geq 65$ & $59(20 \%)$ & $243(80 \%)$ & 12.03 & $5.57-26.0$ & \\
\hline \multicolumn{6}{|l|}{ Gender } \\
\hline male & $56(6 \%)$ & $858(94 \%)$ & 1.00 & - & \multirow{2}{*}{.27} \\
\hline female & $51(8 \%)$ & $627(92 \%)$ & 1.23 & $0.85-1.77$ & \\
\hline \multicolumn{6}{|l|}{ Smoking } \\
\hline no & $69(7 \%)$ & $955(93 \%)$ & 1.00 & - & \multirow{3}{*}{.73} \\
\hline yes & $31(6 \%)$ & $457(94 \%)$ & 0.94 & $0.63-1.42$ & \\
\hline unknown & $7(9 \%)$ & $73(91 \%)$ & 1.30 & $0.62-2.73$ & \\
\hline \multicolumn{6}{|l|}{ Alcohol } \\
\hline no & $61(8 \%)$ & $710(92 \%)$ & 1.00 & - & \multirow{3}{*}{.18} \\
\hline yes & $37(6 \%)$ & $631(94 \%)$ & 0.70 & $0.47-1.04$ & \\
\hline unknown & $9(6 \%)$ & $144(94 \%)$ & 0.74 & $0.38-1.46$ & \\
\hline \multicolumn{6}{|l|}{ Drug use } \\
\hline no & $89(7 \%)$ & l,188 (93\%) & 1.00 & - & \multirow{3}{*}{.71} \\
\hline yes & $9(5 \%)$ & $158(95 \%)$ & 0.77 & $0.40-1.51$ & \\
\hline unknown & $9(6 \%)$ & $139(94 \%)$ & 0.87 & $0.45-1.70$ & \\
\hline \multicolumn{6}{|l|}{ Diabetes } \\
\hline no & $78(6 \%)$ & $1,233(94 \%)$ & 1.00 & - & \multirow{3}{*}{.006} \\
\hline yes & $22(12 \%)$ & $157(88 \%)$ & 2.07 & $1.32-3.23$ & \\
\hline unknown & $7(7 \%)$ & $95(93 \%)$ & 1.15 & $0.55-2.43$ & \\
\hline \multicolumn{6}{|l|}{ Previous Cardiac Incident } \\
\hline no & $83(6 \%)$ & $1,316(94 \%)$ & 1.00 & - & \multirow{3}{*}{$<.001$} \\
\hline yes & $16(17 \%)$ & $78(83 \%)$ & 2.87 & $1.75-4.70$ & \\
\hline unknown & $8(8 \%)$ & $91(92 \%)$ & 1.36 & $0.68-2.73$ & \\
\hline BMI & $28.6(7.3)$ & $27.6(6.5)$ & & & .16 \\
\hline underweight $(<18.5)$ & $9(6 \%)$ & $131(94 \%)$ & 1.00 & 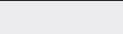 & \multirow{5}{*}{.30} \\
\hline normal $(18.5-<25)$ & $33(6 \%)$ & $477(94 \%)$ & & & \\
\hline overweight $(25-<30)$ & $29(6 \%)$ & $474(94 \%)$ & 0.89 & $0.56-1.41$ & \\
\hline obese $(30-<35)$ & $18(7 \%)$ & $251(93 \%)$ & 1.04 & $0.61-1.77$ & \\
\hline$\geq 35$ & $18(11 \%)$ & $152(89 \%)$ & 1.64 & $0.97-2.77$ & \\
\hline $\begin{array}{l}\text { Charlson comorbidity adjusted for diabetes and } \\
\text { pulmonary disease, mean (sd) }\end{array}$ & $2.2(1.6)$ & $1.5(1.4)$ & & & $<.001$ \\
\hline 0 & $10(3 \%)$ & $306(97 \%)$ & 1.00 & - & \\
\hline 1 & $35(5 \%)$ & $664(95 \%)$ & 1.58 & $0.79-3.15$ & \\
\hline 2 & $24(10 \%)$ & $228(90 \%)$ & 3.01 & $1.47-6.18$ & \\
\hline 3 & $14(10 \%)$ & $126(90 \%)$ & 3.16 & $1.44-6.94$ & $<.001$ \\
\hline 4 & $13(12 \%)$ & $97(88 \%)$ & 3.73 & $1.69-8.27$ & \\
\hline$\geq 5$ & $11(15 \%)$ & $64(85 \%)$ & 4.63 & $2.04-10.5$ & \\
\hline \multicolumn{6}{|l|}{ Diagnosis group } \\
\hline degenerative & $61(6 \%)$ & $931(94 \%)$ & 1.00 & - & \\
\hline trauma & $29(8 \%)$ & $343(92 \%)$ & 1.27 & $0.83-1.94$ & 36 \\
\hline neoplasm & $6(5 \%)$ & $111(95 \%)$ & 0.83 & $0.37-1.89$ & \\
\hline other & $11(10 \%)$ & $100(90 \%)$ & 1.61 & $0.87-2.97$ & \\
\hline Diagnosis level & & & & & \\
\hline lumbar & $31(5 \%)$ & $551(95 \%)$ & 1.00 & - & \\
\hline cervical & $58(8 \%)$ & $696(92 \%)$ & 1.44 & $0.95-2.20$ & \\
\hline thoracic & $18(7 \%)$ & $223(93 \%)$ & 1.40 & $0.80-2.46$ & .25 \\
\hline sacral & 0 & $13(100 \%)$ & - & - & \\
\hline Revision & & & & & \\
\hline no & $75(6 \%)$ & $1,231(94 \%)$ & 1.00 & - & \\
\hline yes & $32(11 \%)$ & $254(89 \%)$ & 1.95 & $1.31-2.89$ & $<.001$ \\
\hline Surgical approach & & & & & \\
\hline posterior & $50(5 \%)$ & $884(95 \%)$ & 1.00 & - & \\
\hline anterior & $14(5 \%)$ & $278(95 \%)$ & 0.90 & $0.50-1.60$ & $<.001$ \\
\hline combined & $43(12 \%)$ & $323(88 \%)$ & 2.19 & $1.49-3.24$ & \\
\hline Invasiveness index, mean (SD) & $8.2(7.3)$ & $12.6(9.9)$ & & & $<.001$ \\
\hline $1-5$ & $37(5 \%)$ & $696(95 \%)$ & 1.00 & - & \\
\hline $6-10$ & $15(4 \%)$ & $385(96 \%)$ & 0.72 & $0.40-1.30$ & \\
\hline $11-15$ & $24(10 \%)$ & $216(90 \%)$ & 1.98 & $1.21-3.24$ & \\
\hline $16-20$ & $11(12 \%)$ & $81(88 \%)$ & 2.37 & $1.25-4.48$ & $<.001$ \\
\hline $21-25$ & $8(17 \%)$ & $39(83 \%)$ & 3.37 & $1.67-6.82$ & \\
\hline$>25$ & $12(17 \%)$ & $58(83 \%)$ & 3.40 & $1.86-6.21$ & \\
\hline
\end{tabular}

$\mathrm{RR}=$ relative risk, $\mathrm{Cl}=$ confidence intervals 
Table 5 Multivariate analysis of relative risk for pulmonary adverse occurrence

\begin{tabular}{llll}
\hline Risk factors & RR & $\mathbf{9 5 \%} \mathbf{C l}$ & $\boldsymbol{P}$-value \\
\hline Gender (female) & 1.10 & $0.77-1.59$ & .60 \\
\hline Diabetes (yes) & 1.13 & $0.71-1.72$ & .58 \\
\hline Smoking (yes) & 1.32 & $0.86-1.95$ & .19 \\
\hline Previous cardiac event (yes) & 1.26 & $0.75-1.98$ & .35 \\
\hline Revision (yes) & 1.39 & $0.38-1.22$ & .09 \\
\hline Age (years) & & & \\
\hline 18-39 & 1.00 & - & - \\
\hline $40-64$ & 2.21 & $1.06-5.40$ & .05 \\
\hline$\geq 65$ & 8.10 & $3.87-19.8$ & $<.001^{*}$ \\
\hline BMI & & & \\
\hline Underweight/ Normal (<25) & 1.00 & - & - \\
\hline Overweight (25-<30) & 0.81 & $0.52-1.26$ & .35 \\
\hline Obese (30-<35) & 0.85 & $0.50-1.39$ & .53 \\
\hline$>35$ & 1.44 & $0.85-2.34$ & .16 \\
\hline Charlson Comorbidity Adjusted & & & \\
\hline 0 & 1.00 & - & - \\
\hline 1 & 1.42 & $0.75-2.96$ & .31 \\
\hline 2 & 1.81 & $0.93-3.86$ & .10 \\
\hline 3 & 1.73 & $0.81-3.87$ & .17 \\
\hline$\geq 4$ & 2.42 & $1.24-5.15$ & $.01^{*}$ \\
\hline Invasiveness index & & & $.03 *$ \\
\hline $1-5$ & 1.00 & - & - \\
\hline 6 - 10 & 0.70 & $0.38-1.22$ & .22 \\
\hline$\geq 11$ & 1.57 & $1.05-2.38$ & \\
\hline
\end{tabular}

*Significant, $\mathrm{RR}=$ relative risk, $\mathrm{Cl}=$ confidence intervals

\section{DISCUSSION}

- The incidence of cardiac complications after spine surgery was $6.7 \%$. Reported cardiac complication rates after spine surgery range from $0.5 \%$ to $9.5 \%[1,2,7,9,11]$.

- Our reported rate of cardiac complications is on the higher end of those previously reported from other centers. There are a number of factors to consider. First, all cardiac complications that occurred within 2 years after spine surgery were assessed for. This very inclusive approach likely overestimates the actual number of cardiac occurrences that were directly attributable to the index procedure. In addition, every facility has its own 'footprint' of complications. This is in part due to the unique patient collective it serves, the practice environment and treatment preferences of its medical practitioners as well as administrative factors pertaining to data collection and quality assurance. Thresholds used to identify and code certain conditions may differ from one institution to another. Prospective data gathering usually also has a tendency to increase reporting of highlighted events, such as complications. In our case our facilities serve as a tertiary care referral center and Level 1 Trauma center. Thus a negative patient selection may be present in form of sicker and more seriously ill patients. Our facilities also serve as teaching institutions, with variable background experiences ranging from beginners to extremely experienced providers possibly affecting adverse outcomes rates.

- Though the results of the present study may seem intuitive, the influence of these risk factors has been questioned in the literature $[2,7,11]$.

- Diabetes and previous cardiac history were not identified as risk factors in the multivariate analysis. This may be due in part to the relative infrequent number of cardiac complications, which resulted in wide confidence intervals and low power to detect a clinically important difference.

- We observed more than an eight fold increase in risk for patients older than 65 years, even when controlling for all other potential confounding risk factors.

- Strengths: This is a large prospectively enrolled patient cohort with wide-ranging data sets that allow us to utilize multivariate analysis to examine risk factors for cardiac complications after spine surgery.

- Limitations: The binary representation of some data demonstrates the presence of disease, but not the severity and this may have potentially confounded the results, particularly in the multivariate analysis. 
- Future research should investigate prediction models whereby the probability of a cardiac adverse outcome can be predicted for each patient who undergoes spine surgery based on their composite of risk factors. This prediction model would need to be externally validated in another population of spine surgery patients.

\section{SUMMARY AND CONCLUSIONS}

- In this study, the incidence of cardiac complications after spine surgery was $6.7 \%$ with a mortality rate of 2.36 per 1000 persons per year.

- Risk factors for cardiac complications after spine surgery include age $>65$ years, diabetes, previous cardiac history, revision surgery, elevated Charlson morbidity score, greater surgical invasiveness [14].

\section{REFERENCES}

1. Carreon LY, Puno RM, Dimar JR 2nd, et al (2003) Perioperative complications of posterior lumbar decompression and arthrodesis in older adults. J Bone Joint Surg Am; 85-A(11):20892092.

2. Cassinelli EH, Eubanks J, Vogt M, et al (2007) Risk factors for the development of perioperative complications in elderly patients undergoing lumbar decompression and arthrodesis for spinal stenosis: an analysis of 166 patients. Spine; 32(2): 230235.

3. Deyo RA, Cherkin DC, Loeser JD, et al (1992) Morbidity and mortality in association with operations on the lumbar spine. The influence of age, diagnosis, and procedure. J Bone Joint Surg Am; 74(4):536-543.

4. Faciszewski T, Jensen R, Rokey $\mathbf{R}$, et al (2001) Cardiac risk stratification of patients with symptomatic spinal stenosis. Clin Orthop Relat Res; (384):110-115.

5. Hertzer NR, Beven EG, Young JR, et al (1984) Coronary artery disease in peripheral vascular patients. A classification of 1000 coronary angiograms and results of surgical management. Ann Surg; 199(2):223-233.

6. Kalanithi PS, Patil CG, Boakye M (2009) National complication rates and disposition after posterior lumbar fusion for acquired spondylolisthesis. Spine (Phila Pa 1976); 34(18):19631969.

7. Patel N, Bagan B, Vadera S, et al (2007) Obesity and spine surgery: relation to perioperative complications. J Neurosurg Spine; 6(4):291-297.
8. Raffo CS, Lauerman WC (2006) Predicting morbidity and mortality of lumbar spine arthrodesis in patients in their ninth decade. Spine; 31(1):99-103.

9. Vaidya R, Carp J, Bartol S, et al (2009) Lumbar spine fusion in obese and morbidly obese patients. Spine; 34(5):495-500.

10. Mangano DT (1990) Perioperative cardiac morbidity. Anesthesiology; 72(1):153-184.

11. Lee DY, Lee SH, Jang JS (2007) Risk factors for perioperative cardiac complications after lumbar fusion surgery. Neurol Med Chir (Tokyo); 47(11):495-500.

12. Mirza SK, Deyo RA, Heagerty PJ, et al (2006) Towards standardized measurement of adverse events in spine surgery: conceptual model and pilot evaluation. BMC Musculoskelet Disord; $7: 53$.

13. Mirza SK, Deyo RA, Heagerty PJ, et al (2008) Development of an index to characterize the "invasiveness" of spine surgery: validation by comparison to blood loss and operative time. Spine; 33(24):2651-2661; discussion 2662.

14. Charlson ME, Pompei P, Ales KL, et al (1987) A new method of classifying prognostic comorbidity in longitudinal studies: development and validation. J Chronic Dis; 40(5):373-383.

15. Li G, Patil CG, Lad SP, et al (2008) Effects of age and comorbidities on complication rates and adverse outcomes after lumbar laminectomy in elderly patients. Spine; 33(11):12501255. 


\section{EDITORIAL STAFF PERSPECTIVE}

This study touches upon a type of complication frequently overlooked in spine surgery. Cardiac and other internal medical complications are commonly assumed to be covered by other specialties, such as Anesthesia or Medical specialties and are therefore overlooked by surgical specialties such as ours. However, as this study shows, subspecialties such as Spine have very specific concerns, which are not specifically addressed by anyone but us.

Possible shortcomings of this study concern lack of control of variables typical for a retrospective study such as this. For cardiac conditions this may include perioperative beta-blockade or absence thereof, use of chemical thrombembolism prophylaxis and utilization of Intensive Care facilities for at-risk patients. The value of this study however lies in this cohort size and diversity of conditions treated. It may direct us to utilize preoperative medicine consult services to optimize preoperative preparations for at-risk patients and may help us counsel patients more honestly. 